\title{
Cognitive Impairment Is Associated with a Low Omega-3 Index in the Elderly: Results from the KORA-Age Study
}

\author{
Karoline Lukaschek ${ }^{a, b} \quad$ Clemens von Schacky ${ }^{c, d} \quad$ Johannes Kruse $^{a, e}$ \\ Karl-Heinz Ladwig ${ }^{b}, f$ \\ aDepartment of Psychosomatic Medicine and Psychotherapy, University of Gießen, Gießen, \\ ${ }^{b}$ Helmholtz Zentrum München, Institute of Epidemiology II, Neuherberg, ${ }^{\mathrm{C}}$ Medizinische \\ Klinik und Poliklinik I, University of Munich, Munich, dOmegametrix, Martinsried, \\ e Department of Psychosomatic Medicine and Psychotherapy, University of Marburg, \\ Marburg, and ${ }^{f}$ Department of Psychosomatic Medicine and Psychotherapy, Klinikum rechts \\ der Isar, Technische Universität München, Munich, Germany
}

\section{Key Words}

Cognitive impairment · Omega-3 polyunsaturated fatty acids · Omega-3 index · Elderly population · Population-based study

\begin{abstract}
Background: Omega-3 polyunsaturated fatty acids (PUFA) may affect the risk of cognitive decline in older adults. Methods: Cross-sectional analysis was conducted among 720 (50.4\% women) participants aged 68-92 years (mean age: 77.6, SD \pm 6.2 ) of the population-based KORA-Age study. Eicosapentaenoic acid and docosahexaenoic acid (omega-3 index) were measured in erythrocytes as a percentage of total fatty acids. The categories low $(<5.7)$, intermediate (5.7-6.8), and high ( $>6.8$ ) levels of the omega-3 index were built using tertiles. The association between cognitive status and omega-3 levels was assessed by logistic regression analyses with adjustments for important concurrent risk factors of cognitive decline. Results: In the sex- and age-adjusted model (model 1 ), subjects with a low omega- 3 index were at a significantly higher risk for cognitive impairment (OR: 1.77, 95\% CI: 1.15-2.73, $\mathrm{p}=0.009$ ). This association remained stable after further adjusting for educational level (model 2; OR: 1.75, 95\% CI: 1.13-2.71, $p=0.01$ ) and metabolic risk factors (model 3; OR: 1.77, 95\% CI: 1.14-2.75, $p=0.01$ ). After further controlling for affective disorders (model 4), the association did not attenuate (OR: $1.77,95 \% \mathrm{CI}: 1.14-2.76, \mathrm{p}=0.01)$. Conclusion: A robust association was found between low omega-3 levels and cognitive impairment in an elderly population. Further research is needed to understand the link between omega-3 PUFA and cognitive functioning.
\end{abstract}


Lukaschek et al.: Cognitive Impairment Is Associated with a Low Omega-3 Index in the Elderly: Results from the KORA-Age Study

\section{Introduction}

A growing body of evidence suggests that the two omega-3 polyunsaturated fatty acids (PUFA) eicosapentaenoic acid (EPA) and docosahexaenoic acid (DHA) could have neuroprotective properties $[1,2]$. With ageing, omega-3 PUFA levels in the brain tend to decrease, suggesting that low levels of EPA and DHA could contribute to deterioration in memory and other cognitive functions [3]. Many of the benefits of DHA may be due its derivative neuroprotection D1 (NPD1), which helps promote membrane fluidity, regulate apoptosis, and modulate inflammation [4]. EPA plays a major role in the modulation of blood flow and inflammation [2]. Both EPA and DHA potentially play a role in synaptic plasticity, neurogenesis, cognition, and vascular health $[5,6]$.

Notwithstanding the biological plausibility that explains the potential protective role of omega-3 PUFAs [5, 6], and despite considerable efforts in the last decade, interventional trials regarding the effect of omega-3 do not univocally show an inverse relation between levels of omega-3 PUFAs and cognitive impairment [7-9].

Furthermore, population-based studies on the relationship between blood (plasma or erythrocyte) omega-3 PUFA composition and some form of cognitive impairment yielded inconclusive results [10], either showing a strong relationship between DHA and/or EPA and a vascular pattern of cognitive impairment [11], global cognitive function [12], and major aspects of cognitive performance [13] or failing to show significant associations [13]. In some studies, the association attenuated after adjustment for confounders [14]. Likewise, some longitudinal studies revealed that lower erythrocyte EPA and DHA levels were associated with a higher risk of cognitive decline $[15,16]$. However, this association could not be confirmed by other studies [17-19].

Given the controversial evidence, we hypothesized that erythrocyte EPA and DHA are independent predictors for cognitive impairment. Since cognitive impairment is influenced by a multitude of factors [20-22], we took special effort to control for potential confounding factors. As in the previous Framingham study [11], we chose the HS-Omega-3 Index method, a widely used standardized method to analyze erythrocyte fatty acid composition [23]. Erythrocyte fatty acids have a low biological variability and thus reflect tissue fatty acid composition [24]. We report the association of erythrocyte EPA and DHA with cognitive impairment in a population-based sample of older subjects $(n=720$ participants, mean age: 77.6 years, $\mathrm{SD} \pm 6.2$ ).

\section{Methods}

Study Setting and Population

The KORA (Cooperative Health Research in the Region of Augsburg)-Age study is a population-based study conducted in southern Germany. Between 1984/1985 and 1999/2000, four cross-sectional population-based surveys were conducted in Augsburg and two surrounding counties with response rates from $79 \%$ in the first survey to $67 \%$ in the fourth survey [25]. The KORA-Age cohort includes all participants from those KORA surveys aged 65 years or older at the end of 2008, i.e. born in or before 1943. Details about KORA-Age have been reported elsewhere [26]. Briefly, 1079 participants were examined at baseline in 2009 (KORA-Age 1). In 2012, 822 of these participants took part in a follow-up study including a telephone interview, physical examinations, a face-to-face interview, and a self-assessment form (KORA-Age 2). The participants of KORA-Age 2 provided the data for this cross-sectional study. The examinations and the interviews were performed by trained and experienced staff from the KORA study center in Augsburg. All participants had given informed consent prior to their inclusion in the study. The KORA-Age study was approved by the ethics committee of the Bavarian Medical Association. All investigations have been conducted according to the principles expressed in the Declaration of Helsinki. 
Lukaschek et al.: Cognitive Impairment Is Associated with a Low Omega-3 Index in the

Elderly: Results from the KORA-Age Study

After exclusion of participants with missing data on exposure and outcome variables, the final data set for the present analysis consisted of 720 subjects (online suppl. fig. 1; available on www. karger.com/doi/10.1159/000448805).

\section{Instruments and Procedures}

Exposure: Omega-3 PUFA Concentration and Omega-3 Index

Erythrocyte fatty acid composition was analyzed according to the HS-Omega-3 Index(R) methodology as previously described [27]. Fatty acid methyl esters were generated from erythrocytes by acid transesterification and analyzed by gas chromatography using a GC2010 Gas Chromatograph (Shimadzu, Duisburg, Germany) equipped with a SP2560, 100-meter column (Supelco, Bellefonte, Pa., USA) using hydrogen as carrier gas. Fatty acids were identified by comparison with a standard mixture of fatty acids characteristic of erythrocytes. Results are given as EPA plus DHA expressed as a percentage of total identified fatty acids after response factor correction. The coefficient of variation for EPA plus DHA was 5\%. Analyses were qualitycontrolled according to DIN ISO 15189. The omega-3 index was approximately normally distributed in the study population. The categories low $(<5.7)$, intermediate $(5.7-6.8)$, and high $(>6.8)$ levels of the omega-3 index were built using tertiles [28].

Outcome: Cognitive Status

Cognitive status was assessed by using the German version of the Telephone Interview for Cognitive Status modified (TICS-m), which includes adjustment for years of education [29]. The instrument includes four cognitive domains: (a) orientation; (b) memory (registration, recent memory, and delayed recall); (c) attention/calculation, and (d) language (semantic memory, comprehension and repetition). The TICS-m was administered according to published procedures and followed a standardized script [30]. The TICS-m score ranges from of 0 to 50 [29]. Normal cognitive function was defined as having $\geq 31$ of the TICS-m score; mild cognitive impairment was between 28 and 30, and probable dementia was $\leq 27$ of the TICS-m score [31]. The variable was dichotomized into good (= normal) cognitive status $(\mathrm{n}=561)$ and mildly impaired cognitive status/suspected dementia $(\mathrm{n}=159)$. We tested for differences in the omega-3 index levels between mildly cognitive impaired subjects $(n=105)$ and subjects suffering from suspected dementia $(n=54)$. No difference was detected $\left(\chi^{2}=0.17\right.$, d.f. $\left.=2, p=0.92\right)$, thus supporting our decision of combining those two categories into one.

\section{Confounders}

We chose a variety of known and potential risk factors for cognitive decline as confounders [22]. Socioeconomic variables included age and sex. Living alone was recorded in the telephone interview and assessed by a one-item instrument with a yes/no answer. Education level was dichotomized in $<12$ years and $\geq 12$ years of schooling. Physical activity was dichotomized into physically active or physically inactive. Individuals were rated as 'active', if they reported regularly participating in sports for $1 \mathrm{~h} /$ week on average during leisure time in either season. Current smoking was defined as regularly or occasionally smoking cigarettes. Following WHO recommendations, obesity was defined as a BMI $\geq 30$ and hypertension as a (systolic/ diastolic) blood pressure $\geq 140 / 90 \mathrm{~mm} \mathrm{Hg}$ or taking antihypertensive medication. Total cholesterol (TC) and high-density lipoprotein cholesterol (HDL-C) were measured in mg/dl by enzymatic methods (CHOD-PAP; Boehringer, Mannheim, Germany) and combined to TC/HDL-C for the present analyses. Hypercholesterolemia was defined as a TC/HDL-C ratio $>5$. Depression was measured in the telephone interview by the Geriatric Depression Scale (GDS-15) from Sheikh and Yesavage [32]. This scale comprises 15 items with yes/ no answers. The maximal score is 15 points, where $0-5$ indicates normal, 6-10 light-to-moderate depression, and 11-15 severe depression. Participants with a score $\geq 10$ were considered to have depressive symptoms. Anxiety was assessed using the Generalized Anxiety Disorder Scale-7 (GAD-7) [33]. The GAD-7 consists of 7 items with answers ranging from 'not at all' (0) to 'nearly every day' (3). Thus, the score ranges from 0 to 21. In the present investigation, participants with a score $\geq 10$ were considered to have anxiety. Sleep-related characteristics were evaluated in the interview using the Uppsala Sleep Inventory (USI) [34]. Two separate 3-category interview questions were asked concerning an individual's difficulty initiating sleep ('Do you have trouble falling asleep?') and the difficulty maintaining sleep ('Do you wake up during the night?'). Individuals were considered to have difficulties if they answered 'often' or 'sometimes' and were compared to participants who answered 'almost never' in response to the questions. 
Dementia

Cognitive Disorders

\begin{tabular}{l|l}
\hline \multicolumn{2}{l|}{ Dement Geriatr Cogn Disord 2016;42:236-245 } \\
\hline DOI: $10.1159 / 000448805$ & $\begin{array}{l}\text { C 2016 S. Karger AG, Basel } \\
\text { www.karger.com/dem }\end{array}$ \\
\hline
\end{tabular}

Lukaschek et al.: Cognitive Impairment Is Associated with a Low Omega-3 Index in the Elderly: Results from the KORA-Age Study

Table 1. Association of socioeconomic, lifestyle, and metabolic risk factors with low ( $<5.7)$, intermediate (5.7-6.8), and high (>6.8) levels of the omega-3 index $(n=720)$

\begin{tabular}{|c|c|c|c|c|}
\hline Omega-3 index & $\begin{array}{l}\text { Low } \\
(n=240)\end{array}$ & $\begin{array}{l}\text { Intermediate } \\
(\mathrm{n}=240)\end{array}$ & $\begin{array}{l}\text { High } \\
(n=240)\end{array}$ & $\mathrm{p}$ value \\
\hline \multicolumn{5}{|l|}{ Socioeconomic factors } \\
\hline Sex & & & & 0.94 \\
\hline Men & $50.4(121)$ & $48.8(117)$ & $49.6(119)$ & \\
\hline Women & $49.6(119)$ & $51.2(123)$ & $50.4(121)$ & \\
\hline Age & & & & 0.004 \\
\hline$<78$ years & $52.1(125)$ & $60.0(144)$ & $42.5(102)$ & \\
\hline $78-88$ years & $40.0(96)$ & $35.0(84)$ & $48.8(117)$ & \\
\hline$\geq 88$ years & $7.9(19)$ & $5.0(12)$ & $8.8(21)$ & \\
\hline Education $\geq 12$ years & $22.5(54)$ & $26.3(63)$ & $36.7(88)$ & 0.002 \\
\hline Living alone & $39.2(94)$ & $30.0(72)$ & $36.3(87)$ & 0.10 \\
\hline \multicolumn{5}{|l|}{ Metabolic risk factors } \\
\hline Physical inactivity (sporting < 1 h/week) & $43.8(105)$ & $41.3(99)$ & $47.5(114)$ & 0.38 \\
\hline Current smoking & $2.9(7)$ & $4.2(10)$ & $3.3(8)$ & 0.75 \\
\hline Obesity (BMI $\geq 30)$ & $31.7(76)$ & $27.5(66)$ & $23.8(57)$ & 0.15 \\
\hline Hypertension ( $\geq 140 / 90$ mm Hg) & $68.3(164)$ & $67.1(161)$ & $75.8(182)$ & 0.08 \\
\hline Type 2 diabetes mellitus & $15.4(37)$ & $16.7(40)$ & $15.8(38)$ & 0.92 \\
\hline Hypercholesterolemia (TC/HDL-C ratio $>5$ ) & $16.7(40)$ & $20.4(49)$ & $15.0(36)$ & 0.28 \\
\hline
\end{tabular}

Values are presented as percentages with numbers in parentheses.

Statistical Analysis

Univariate associations were assessed using the $\chi^{2}$ test or Fisher exact test (in case the cell count was $<5$ ). To assess the association between omega-3 index levels (exposure) and cognitive status (outcome), multinomial logistic regression analyses with different adjustments for potential confounding factors were performed. The first model (model 1) was adjusted for age and sex, the second model (model 2) was additionally adjusted for education, the third model (model 3) additionally for metabolic risk factors (obesity, actual hypertension, hypercholesterolemia, smoking, and physical inactivity) and the final model (model 4) additionally for depression and anxiety.

For all statistical analyses, a p value $<0.05$ was considered to be statistically significant. All evaluations were performed with the statistical software SAS Version 9.3 for Windows (SAS Institute, Cary, N.C., USA). The study follows the STROBE guidelines for observational studies [35].

\section{Results}

\section{Description of the Study Population}

The population under study consisted of a total of 720 participants, among them 357 $(49.6 \%)$ men and $363(50.4 \%)$ women in an age range between 68 and 92 years (mean age: $77.6, \mathrm{SD} \pm 6.2$ ). The mean omega-3 index score was 6.4 (range: $3.15-12.95, \mathrm{SD} \pm 1.4$ ). One third each $(n=240)$ of the study population showed low, intermediate, or high levels of the omega-3 index. The characteristics of the study population stratified for omega-3 index levels are given in table 1. Compared to subjects with low levels, participants with high levels were significantly better educated, older, and less likely to suffer from anxiety. No significant differences were observed regarding sex, living alone, metabolic risk factors including sleep problems, and depressed mood. 
Lukaschek et al.: Cognitive Impairment Is Associated with a Low Omega-3 Index in the Elderly: Results from the KORA-Age Study

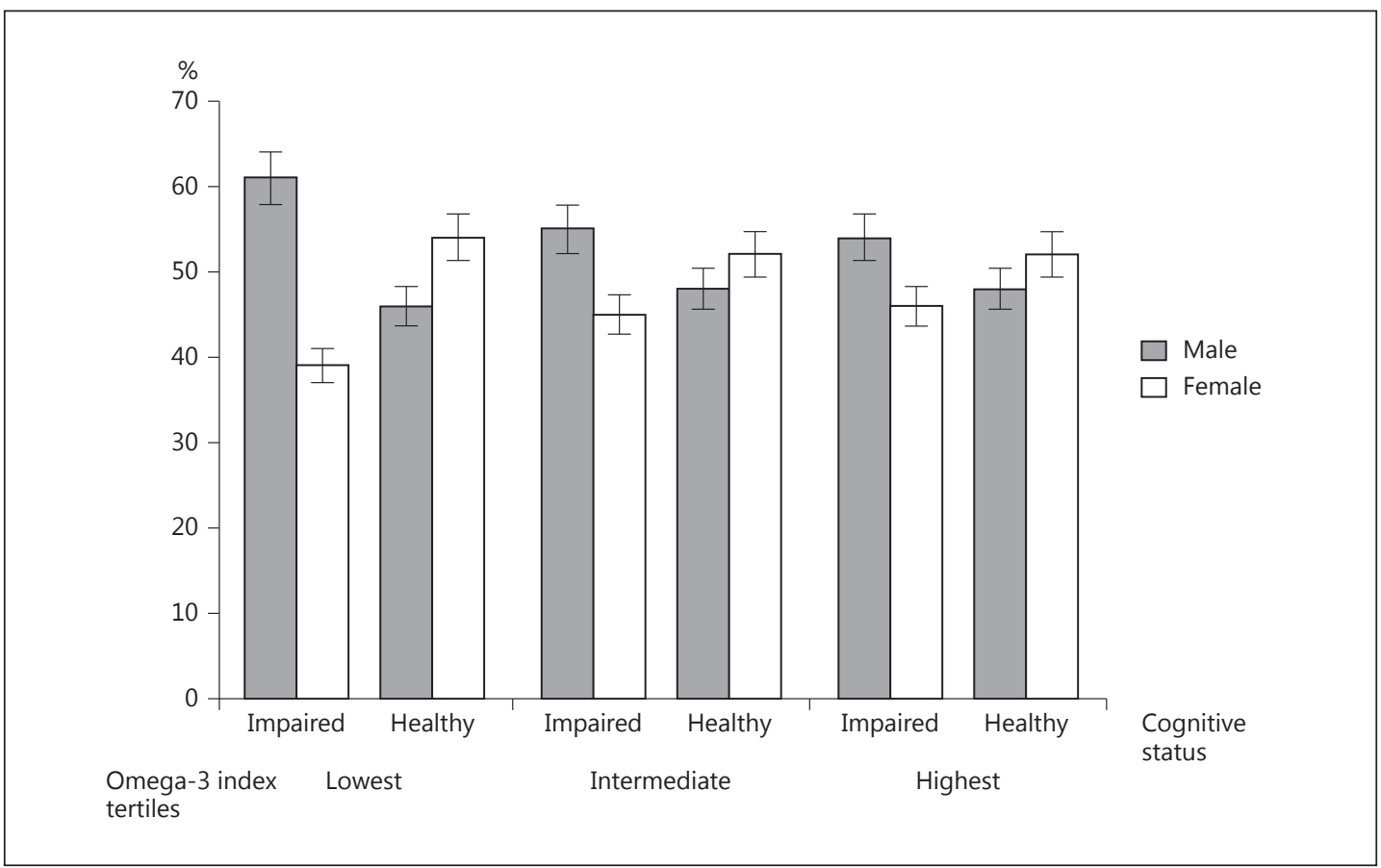

Fig. 1. Percentage of participants with healthy or impaired cognitive status per omega-3 index tertile (separately for men and women).

\section{Distribution of Healthy and Cognitively Impaired Participants}

In the lowest omega-3 tertile, the percentage of cognitively impaired participants was highest $(n=71,29.6 \%)$, whereas in the intermediate tertile, this percentage was $15.8 \%(n=$ $38)$, and in the highest tertile it was $20.8 \%(n=50)$. This difference of distribution was significant $\left(\chi^{2}=13.51\right.$, d.f. $\left.=2, p=0.001\right)$. As can be seen in figure 1 , in each omega- 3 tertile, more men than women were in the cognitively impaired group. However, the observed difference between the sexes was significant only in the lowest omega-3 tertile $\left(\chi^{2}=4.15\right.$, d.f. $=1, p=$ $0.04)$.

\section{Associations of Omega-3 Index Levels with Cognitive Status by Logistic Regression}

(Table 2)

In the sex- and age-adjusted model (model 1), subjects with a low omega-3 index level were at a significantly higher risk for mild cognitive impairment/suspected dementia (OR: 1.77, 95\% CI: 1.15-2.73, $\mathrm{p}=0.009$ ). This association remained stable after further adjusting for educational level (model 2; OR: 1.75, 95\% CI: 1.13-2.71, $\mathrm{p}=0.01$ ) and additionally for metabolic risk factors (obesity, hypertension, hypercholesterolemia, smoking, and physical inactivity) (model 3; OR: 1.77, 95\% CI: 1.14-2.75, p = 0.01). Even after further controlling for affective disorders (depression and anxiety) in the final model (model 4), the association did not attenuate (OR: 1.77, 95\% CI: 1.14-2.76, $\mathrm{p}=0.01$ ). The model fit for all models was sufficient as indicated by the c statistic $(0.69)$.

\section{Sensitivity Analyses: Sleep Problems}

In a reduced data set $(n=715)$, no significant associations were found between omega-3 index levels and initiating sleep $\left(\chi^{2}=3.47\right.$, d.f. $\left.=2, p=0.18\right)$, maintaining sleep $\left(\chi^{2}=3.51\right.$, 
Lukaschek et al.: Cognitive Impairment Is Associated with a Low Omega-3 Index in the Elderly: Results from the KORA-Age Study

Table 2. Associations of the omega- 3 index levels with cognitive decline (159 cases, 561 non-cases) adjusted for different risk factors (models $1-4$ )

\begin{tabular}{|c|c|c|c|c|}
\hline Covariates & $\begin{array}{l}\text { Model 1, } \\
\text { OR, 95\% CI }\end{array}$ & $\begin{array}{l}\text { Model 2, } \\
\text { OR, 95\% CI }\end{array}$ & $\begin{array}{l}\text { Model 3, } \\
\text { OR, 95\% CI }\end{array}$ & $\begin{array}{l}\text { Model 4, } \\
\text { OR, 95\% CI }\end{array}$ \\
\hline \multicolumn{5}{|l|}{ Omega-3 index levela } \\
\hline Low & $1.77,1.15-2.73^{*}$ & $1.75,1.13-2.71^{*}$ & $1.77,1.14-2.75^{*}$ & $1.77,1.14-2.76^{*}$ \\
\hline Intermediate & $0.85,0.53-1.38$ & $0.84,0.52-1.36$ & $0.85,0.52-1.39$ & $0.86,0.53-1.40$ \\
\hline \multicolumn{5}{|l|}{ Age $^{\mathrm{b}}$} \\
\hline $77-88$ years & $2.24,1.51-3.32^{* *}$ & $2.25,1.52-3.33^{* *}$ & $2.05,1.36-3.07^{*}$ & $2.05,1.37-3.09^{*}$ \\
\hline$\geq 88$ years & $4.90,2.59-9.25^{* *}$ & $4.85,2.56-9.18^{* *}$ & $4.14,2.15-7.98^{* *}$ & $4.15,2.16-8.01^{* *}$ \\
\hline Male & $1.55,1.07-2.24^{*}$ & $1.59,1.08-2.35^{*}$ & $1.70,1.14-2.53^{*}$ & $1.70,1.14-2.53^{*}$ \\
\hline Low education & - & $1.09,0.70-1.68$ & $1.13,0.73-1.76$ & $1.13,0.73-1.76$ \\
\hline Physical inactivity & - & - & $1.49,1.01-2.19^{*}$ & $1.49,1.01-2.19^{*}$ \\
\hline Current smoker & - & - & $0.47,0.13-1.70$ & $0.48,0.13-1.74$ \\
\hline Obesity & - & - & $1.03,0.67-1.56$ & $1.03,0.67-1.56$ \\
\hline Hypertension & - & - & $1.04,0.69-1.56$ & $1.04,0.69-1.56$ \\
\hline Hypercholesterolemia & - & - & $0.83,0.50-1.37$ & $0.83,0.50-1.37$ \\
\hline Anxiety & - & - & - & $1.16,0.49-2.72$ \\
\hline Depression & - & - & - & $0.81,0.24-2.76$ \\
\hline
\end{tabular}

Model 1 was adjusted for age and sex, model 2 was additionally adjusted for education, model 3 additionally for metabolic risk factors (obesity, actual hypertension, hypercholesterolemia, smoking, and physical inactivity), and model 4 additionally for depression and anxiety. ${ }^{*} \mathrm{p}<0.05,{ }^{* *} \mathrm{p}<0.0001$. ${ }^{\text {a The group with }}$ the highest omega- 3 index level $\left(>6.8\right.$ ) was the reference group. ${ }^{b}$ The youngest age group ( $<77$ years of age) was the reference group.

d.f. $=2, p=0.17$ ) or a combination of both $\left(\chi^{2}=3.51\right.$, d.f. $\left.=2, p=0.17\right)$. Impaired sleep patterns were not significantly associated with cognitive impairment when introduced into the final logistic regression model (model 4). However, even in this further adjusted models, the association of cognitive impairment with low omega-3 index levels remained stable (OR: 1.78, 95\% CI: 1.14-2.78, $\mathrm{p}=0.01$ when adjusting for problems initiating sleep; OR: $1.79,95 \% \mathrm{CI}$ : $1.15-2.79, \mathrm{p}=0.01$ when adjusting for problems maintaining sleep; OR: $1.78,95 \% \mathrm{CI}: 1.14-$ $2.77, \mathrm{p}=0.01$ when adjusting for a combination of both). The model fit for all models was sufficient as indicated by the c statistic (0.69).

\section{Discussion}

A robust association between low omega-3 index levels and cognitive impairment was found in the present study based on data of a large, population-based sample of elderly subjects. The association resisted adjustment for sociodemographic and metabolic risk factors and for affective disorders. Our findings provide further evidence for the neuroprotective role of omega-3 fatty acids against cognitive decline [3] and corroborate previously published data. In a cross-sectional study in dementia-free Framingham study participants ( $\mathrm{n}=1,575$, mean age: 67 years, SD \pm 9 ), low levels of EPA and DHA in erythrocytes were associated with small brain volumes and a vascular pattern of cognitive impairment [11]. Another cross-sectional study from Japan including 158 non-demented participants (mean age: 84.1 years, SD \pm 3.4 ) showed that higher global cognitive function was significantly associated with higher levels of serum EPA and DHA+EPA after controlling for confounders [12]. Nonetheless, there is conflicting evidence from population-based studies of the relationship between blood (plasma 
Lukaschek et al.: Cognitive Impairment Is Associated with a Low Omega-3 Index in the Elderly: Results from the KORA-Age Study

or erythrocyte) omega-3 PUFA composition and some form of cognitive impairment. A study from Italy $(\mathrm{n}=935$, age $>65$ years) found that participants with dementia had significantly lower omega-3 PUFA levels (although not EPA and DHA specifically) than participants with normal cognitive function after adjustment for confounders [14]. Furthermore, there was no statistical difference regarding omega-3 PUFAS between cognitively impaired and normal participants [14]. Another cross-sectional study found DHA, but not EPA, to be associated with major aspects of cognitive performance in healthy adults $(n=280)<55$ years of age [13]. Support for our findings also comes from longitudinal studies. In a 4-year follow-up time of 246 men and women aged 63-75 years, lower erythrocyte EPA and DHA were associated with a higher risk of cognitive decline [15]. This, however, could not be confirmed in an observation of 663 initially non-demented subjects ( $\geq 65$ years of age) [17]. In a US study, lower plasma levels of DHA and EPA were associated with a higher risk of decline in verbal fluency, particularly in hypertensive and dyslipidemic subjects, but not with changes in psychomotor speed or delayed word recall in a 11-year follow-up ( $n=2,251$, age $>50$ years) [16].

In the multivariate model, we controlled for a variety of factors known to have an independent impact on cognitive decline. Male sex and increasing age were strongly associated with cognitive impairment in all models, thereby corroborating previous results [20,36]. Furthermore, physical inactivity was significantly associated with cognitive impairment; physical activity has been found to be a protective factor against cognitive decline [20]. Although sustained exposure to smoking and hypertension $[20,21,37,38]$ has been confirmed risk factors for cognitive decline, we did not find a significant association in our models. Furthermore, other risk factors such as low education or obesity [20,21], hypercholesterolemia [39], depressive mood [22], or difficulty in maintaining sleep [40] were not significantly associated with cognitive impairment in the present study.

In our sample, omega-3 levels were surprisingly high among the older-age groups. We cannot explain this finding, which contrasts the general scientific opinion promoting that the content of omega-3 PUFA in the human brain generally increases with age over the first 2 decades and then levels off [41] or even drops $[3,12]$. However, previous research on cardiovascular patients has shown that a higher omega-3 index was associated with longer survival [42].

Interestingly, we found a significant association of high levels of the omega- 3 index and better education. Comparable findings came from the Heart and Soul Study, where low education levels were associated with low levels of DHA and EPA [43]. Although there is still debate on the social determination of taste and food preferences and their impact on nutritional balance [44], one can assume that subjects with better education, i.e. higher social status, are better informed of healthy dietary components. Following Darmon et al. [45], higher-quality diets are, in general, consumed by better-educated and more affluent people. Conversely, lower quality diets tended to be consumed by groups of lower socioeconomic status and more limited economic means. However, it is of note that a substantial proportion of our study population received their education during World War II and in the immediate post-war period when little choice was possible in food. Furthermore, the intake of EPA and DHA is only one determinant of the omega-3 index [46].

\section{Potential Mechanisms Underlying the Link between Cognitive Functioning and PUFA}

The potential cognitive benefit of omega-3 PUFA may result from targeted modulation of neurogenesis and synaptic plasticity in brain regions that are particularly susceptible to oxidative stress and amyloid burden [6, 7]. As such, the hippocampus, a region thought to govern verbal recall, is sensitive to age-associated brain atrophy in both healthy and impaired individuals [7, 47]. As has been shown, the omega-3 index was positively related to brain and hippocampal volume [48], which plays an important role in memory function. 
Elderly: Results from the KORA-Age Study

\section{Recommendations}

In our study, a low omega-3 index was a powerful predictor of cognitive impairment (OR: 1.77). Increasing the omega- 3 index by increased intake of EPA and DHA is easily feasible [49, 50]. Moreover, a dose of up to $3 \mathrm{~g}$ EPA and DHA per day is considered safe by the Federal Drug Administration and up to 5 g per day by its European counterpart, the European Food Safety Authority [23]. However, issues in bioavailability and a large interindividual variability in the uptake of ingested EPA and DHA suggest an individually targeted approach towards dosing of EPA and DHA. Earlier, we suggested a target range for the omega-3 index of 8-11\% for the cardiovascular area [49]. The present data, with a mean of the upper tertile of $8.02 \pm 1.02$, support this target range in the area of cognitive impairment. Surprisingly, the general public does not associate diet habits with dementia [51].

\section{Strengths and Limitations}

The strength of the study is the focus on elderly subjects taken from a well-established, large population-based data set and the use of a reliable biological measure of omega-3 fatty acid levels. A further strength is the use of a validated instrument to assess cognitive status: the TICS-m [29]. This instrument includes the four cognitive domains orientation, memory, attention/calculation, and language and has been performed in population-based studies under strict assessment regulation and quality control. Furthermore, the erythrocyte membrane fatty acid composition is biologically rather stable: omega-3 PUFAs from red blood cells can be used as biochemical indicators of their corresponding midterm (60-90 days) dietary intakes [15]. This is an advantage to plasma fatty acid concentrations, which fluctuate according to shorter-term intake [52].

Limitations have to be considered, however. We cannot address the impact of the dietary intake of omega-3 PUFAs in the KORA age study [53]. Reverse causation, although highly unlikely, cannot be ruled out. Although the demographic and socioeconomic characteristics of the study population roughly reflect those of the average central European population in general, differences in diet between countries may limit generalizability.

\section{Conclusion}

Low omega-3 index levels are robustly associated with cognitive impairment in the present investigation. This association was not influenced by a variety of confounding factors. Further research is needed to better understand the role of omega-3 PUFA in ageing brain physiology and to explain the link between omega-3 PUFA and cognitive functioning. Our data support the usefulness of conducting an intervention trial with omega- 3 fatty acids in the prevention of cognitive impairment, targeting an omega-3 index of 8-11\%.

\section{Acknowledgments}

The KORA (Cooperative Research in the Region of Augsburg) was initiated and financed by the Helmholtz Zentrum München - German Research Center for Environmental Health, which is funded by the German Federal Ministry of Education and Research and by the State of Bavaria. The KORA-Age project was financed by the German Federal Ministry of Education and Research (BMBF FKZ 01ET0713 and 01ET1003A) as part of the 'Health in old age' program. Omegametrix provided fatty acid analyses free of charge.

\section{Disclosure Statement}

C.v.S. founded Omegametrix, a laboratory for fatty acid analyses. He received lecture fees from BASF, DSM, and consulting fees from Huntsworth Medical. 
Lukaschek et al.: Cognitive Impairment Is Associated with a Low Omega-3 Index in the Elderly: Results from the KORA-Age Study

\section{References}

1 Cole GM, Ma QL, Frautschy SA: Omega-3 fatty acids and dementia. Prostaglandins Leukot Essent Fatty Acids 2009;81:213-221.

2 Huang TL: Omega-3 fatty acids, cognitive decline, and Alzheimer's disease: a critical review and evaluation of the literature. J Alzheimers Dis 2010;21:673-690.

3 Fotuhi M, Mohassel P, Yaffe K: Fish consumption, long-chain omega-3 fatty acids and risk of cognitive decline or Alzheimer disease: a complex association. Nat Clin Pract Neurol 2009;5:140-152.

4 Lukiw WJ, Bazan NG: Docosahexaenoic acid and the aging brain. J Nutr 2008;138:2510-2514.

5 Janssen CI, Kiliaan AJ: Long-chain polyunsaturated fatty acids (LCPUFA) from genesis to senescence: the influence of LCPUFA on neural development, aging, and neurodegeneration. Prog Lipid Res 2014;53:1-17.

6 Denis I, Potier B, Vancassel S, Heberden C, Lavialle M: Omega-3 fatty acids and brain resistance to ageing and stress: body of evidence and possible mechanisms. Ageing Res Rev 2013;12:579-594.

7 Mazereeuw G, Lanctot KL, Chau SA, Swardfager W, Herrmann N: Effects of omega-3 fatty acids on cognitive performance: a meta-analysis. Neurobiol Aging 2012;33:1482 e1417-e1429.

8 Sydenham E, Dangour AD, Lim WS: Omega 3 fatty acid for the prevention of cognitive decline and dementia. Cochrane Database Syst Rev 2012;6:CD005379.

9 Forbes SC, Holroyd-Leduc JM, Poulin MJ, Hogan DB: Effect of nutrients, dietary supplements and vitamins on cognition: a systematic review and meta-analysis of randomized controlled trials. Can Geriatr J 2015;18:231245.

10 Issa AM, Mojica WA, Morton SC, Traina S, Newberry SJ, Hilton LG, Garland RH, Maclean CH: The efficacy of omega-3 fatty acids on cognitive function in aging and dementia: a systematic review. Dement Geriatr Cogn Disord 2006;21:88-96.

11 Tan ZS, Harris WS, Beiser AS, Au R, Himali JJ, Debette S, Pikula A, Decarli C, Wolf PA, Vasan RS, et al: Red blood cell omega-3 fatty acid levels and markers of accelerated brain aging. Neurology 2012;78:658-664.

12 Nishihira J, Tokashiki T, Higashiuesato Y, Willcox DC, Mattek N, Shinto L, Ohya Y, Dodge HH: Associations between serum omega-3 fatty acid levels and cognitive functions among community-dwelling octogenarians in Okinawa, Japan: the KOCOA Study. J Alzheimers Dis 2016;51:857-866.

13 Muldoon MF, Ryan CM, Sheu L, Yao JK, Conklin SM, Manuck SB: Serum phospholipid docosahexaenonic acid is associated with cognitive functioning during middle adulthood. J Nutr 2010;140:848-853.

14 Cherubini A, Andres-Lacueva C, Martin A, Lauretani F, Iorio AD, Bartali B, Corsi A, Bandinelli S, Mattson MP, Ferrucci L: Low plasma N-3 fatty acids and dementia in older persons: the InCHIANTI study. J Gerontol A Biol Sci Med Sci 2007;62:1120-1126.

15 Heude B, Ducimetiere P, Berr C, Study EVA: Cognitive decline and fatty acid composition of erythrocyte membranes - The EVA Study. Am J Clin Nutr 2003;77:803-808.

16 Beydoun MA, Kaufman JS, Satia JA, Rosamond W, Folsom AR: Plasma n-3 fatty acids and the risk of cognitive decline in older adults: the Atherosclerosis Risk in Communities Study. Am J Clin Nutr 2007;85:1103-1111.

17 Kroger E, Verreault R, Carmichael PH, Lindsay J, Julien P, Dewailly E, Ayotte P, Laurin D: Omega-3 fatty acids and risk of dementia: the Canadian Study of Health and Aging. Am J Clin Nutr 2009;90:184-192.

18 Manzato E, Roselli della Rovere G, Zambon S, Romanato G, Corti MC, Sartori L, Baggio G, Crepaldi G: Cognitive functions are not affected by dietary fatty acids in elderly subjects in the Pro.V.A. study population. Aging Clin Exp Res 2003;15:83-86.

19 Engelhart MJ, Ruitenberg A, Meijer J, Kiliaan A, van Swieten JC, Hofman A, Witteman JC, Breteler MM: Plasma levels of antioxidants are not associated with Alzheimer's disease or cognitive decline. Dement Geriatr Cogn Disord 2005;19:134-139.

20 Baumgart M, Snyder HM, Carrillo MC, Fazio S, Kim H, Johns H: Summary of the evidence on modifiable risk factors for cognitive decline and dementia: a population-based perspective. Alzheimers Dement 2015;11: 718-726.

21 Beydoun MA, Beydoun HA, Gamaldo AA, Teel A, Zonderman AB, Wang Y: Epidemiologic studies of modifiable factors associated with cognition and dementia: systematic review and meta-analysis. BMC Public Health 2014; 14:643.

22 Plassman BL, Williams JW Jr, Burke JR, Holsinger T, Benjamin S: Systematic review: factors associated with risk for and possible prevention of cognitive decline in later life. Ann Intern Med 2010;153:182-193.

23 von Schacky C: Omega-3 fatty acids in cardiovascular disease - an uphill battle. Prostaglandins Leukot Essent Fatty Acids 2015;92:41-47.

24 Harris WS, Thomas RM: Biological variability of blood omega-3 biomarkers. Clin Biochem 2010;43:338-340.

25 Holle R, Happich M, Lowel H, Wichmann HE, Group MKS: KORA - a research platform for population based health research. Gesundheitswesen 2005;67(suppl 1):S19-S25.

26 Peters A, Doring A, Ladwig KH, Meisinger C, Linkohr B, Autenrieth C, Baumeister SE, Behr J, Bergner A, Bickel $\mathrm{H}$ et al: Multimorbidity and successful aging: the population-based KORA-Age study (in German). Z Gerontol Geriatr 2011;44(suppl 2):41-54.

27 Kohler A, Bittner D, Low A, von Schacky C: Effects of a convenience drink fortified with n-3 fatty acids on the n-3 index. Br J Nutr 2010;104:729-736. 
Lukaschek et al.: Cognitive Impairment Is Associated with a Low Omega-3 Index in the

Elderly: Results from the KORA-Age Study

28 Baek D, Park Y: Association between erythrocyte n-3 polyunsaturated fatty acids and biomarkers of inflammation and oxidative stress in patients with and without depression. Prostaglandins Leukot Essent Fatty Acids 2013;89:291-296.

29 Lacruz M, Emeny R, Bickel H, Linkohr B, Ladwig K: Feasibility, internal consistency and covariates of TICS-m (telephone interview for cognitive status-modified) in a population-based sample: findings from the KORA-Age study. Int J Geriatr Psychiatry 2013;28:971-978.

30 Plassman BL, Newman TT, Welsh KA, Helms MJ, Breitner JC: Properties of the telephone interview for cognitive status: application in epidemiological and longitudinal studies. Neuropsychiatry, Neuropsychol Behav Neurol 1994; 7:235-241.

31 Knopman DS, Roberts RO, Geda YE, Pankratz VS, Christianson TJ, Petersen RC, Rocca WA: Validation of the telephone interview for cognitive status-modified in subjects with normal cognition, mild cognitive impairment, or dementia. Neuroepidemiology 2010;34:34-42.

32 Sheikh JI, Yesavage JA: A knowledge assessment test for geriatric psychiatry. Hosp Community Psychiatry 1985;36:1160-1166.

33 Spitzer RL, Kroenke K, Williams JB, Lowe B: A brief measure for assessing generalized anxiety disorder: the GAD-7. Arch Intern Med 2006;166:1092-1097.

34 Mallon L, Hetta J: A survey of sleep habits and sleeping difficulties in an elderly Swedish population. Ups J Med Sci 1997;102:185-197.

35 von Elm E, Altman DG, Egger M, Pocock SJ, Gotzsche PC, Vandenbroucke JP, Initiative S: The Strengthening the Reporting of Observational Studies in Epidemiology (STROBE) statement: guidelines for reporting observational studies. Lancet 2007;370:1453-1457.

36 Roberts RO, Geda YE, Knopman DS, Cha RH, Pankratz VS, Boeve BF, Tangalos EG, Ivnik RJ, Rocca WA, Petersen RC: The incidence of MCI differs by subtype and is higher in men: the Mayo Clinic Study of Aging. Neurology 2012;78:342-351.

37 Okusaga O, Stewart MC, Butcher I, Deary I, Fowkes FG, Price JF: Smoking, hypercholesterolaemia and hypertension as risk factors for cognitive impairment in older adults. Age Ageing 2013;42:306-311.

38 Hughes TM, Sink KM: Hypertension and its role in cognitive function: current evidence and challenges for the future. Am J Hypertens 2016;29:149-157.

39 Blom K, Emmelot-Vonk MH, Koek HL: The influence of vascular risk factors on cognitive decline in patients with dementia: a systematic review. Maturitas 2013;76:113-117.

40 Johar H, Kawan R, Emeny RT, Ladwig KH: Impaired sleep predicts cognitive decline in old people: findings from the prospective KORA Age Study. Sleep 2016;39:217-226.

41 Cederholm T, Salem N Jr, Palmblad J: Omega-3 fatty acids in the prevention of cognitive decline in humans. Adv Nutr 2013;4:672-676.

42 Kleber ME, Delgado GE, Lorkowski S, Marz W, von Schacky C: Trans-fatty acids and mortality in patients referred for coronary angiography: the Ludwigshafen Risk and Cardiovascular Health Study. Eur Heart J 2016; 37:1072-1078.

43 Cohen BE, Garg SK, Ali S, Harris WS, Whooley MA: Red blood cell docosahexaenoic acid and eicosapentaenoic acid concentrations are positively associated with socioeconomic status in patients with established coronary artery disease: data from the Heart and Soul Study. J Nutr 2008;138:1135-1140.

44 De Henauw S, Matthys C, De Backer G: Socio-economic status, nutrition and health. Arch Public Health 2003; 61:15-31.

45 Darmon N, Drewnowski A: Does social class predict diet quality? Am J Clin Nutr 2008;87:1107-1117.

46 Harris WS, Pottala JV, Lacey SM, Vasan RS, Larson MG, Robins SJ: Clinical correlates and heritability of erythrocyte eicosapentaenoic and docosahexaenoic acid content in the Framingham Heart Study. Atherosclerosis 2012;225:425-431.

47 Samieri C, Maillard P, Crivello F, Proust-Lima C, Peuchant E, Helmer C, Amieva H, Allard M, Dartigues JF, Cunnane SC, et al: Plasma long-chain omega-3 fatty acids and atrophy of the medial temporal lobe. Neurology 2012;79:642-650.

48 Pottala JV, Yaffe K, Robinson JG, Espeland MA, Wallace R, Harris WS: Higher RBC EPA + DHA corresponds with larger total brain and hippocampal volumes: WHIMS-MRI study. Neurology 2014;82:435-442.

49 von Schacky C: The Omega-3 Index as a risk factor for cardiovascular diseases. Prostaglandins Other Lipid Mediat 2011;96:94-98.

50 Joffre C, Nadjar A, Lebbadi M, Calon F, Laye S: n-3 LCPUFA improves cognition: the young, the old and the sick. Prostaglandins Leukot Essent Fatty Acids 2014;91:1-20.

51 Low LF, Anstey KJ: The public's perception of the plausibility of dementia risk factors is not influenced by scientific evidence. Dement Geriatr Cogn Disord 2007;23:202-206.

52 Arab L: Biomarkers of fat and fatty acid intake. J Nutr 2003;133(suppl 3):925S-932S.

53 Schwab S, Heier M, Schneider A, Fischer B, Huth C, Peters A, Thorand B: The use of dietary supplements among older persons in southern Germany - results from the Kora-Age Study. J Nutr Health Aging 2014;18:510-519. 